\title{
STRATEGIC FORESIGHT USING AN ANALYTIC HIERARCHY PROCESS: ENVIRONMENTAL IMPACT ASSESSMENT OF THE ELECTRIC GRID IN 2025.
}

\author{
Ronald Mac-Ginty* \\ Industrial Engineering Department \\ University of Santiago of Chile \\ Santiago, Chile \\ Email: ronald.macginty@usach.cl \\ Raúl Carrasco \\ Industrial Engineering Department \\ University of Santiago of Chile \\ Santiago, Chile \\ Email: raul.carrasco@usach.cl \\ Astrid Oddershede \\ Industrial Engineering Department \\ University of Santiago of Chile \\ Santiago, Chile \\ Email: astrid.oddershede@usach.cl \\ Manuel Vargas \\ Industrial Engineering Department \\ University of Santiago of Chile \\ Santiago, Chile \\ Email: manuel.vargasg@usach.cl
}

\begin{abstract}
This paper presents a strategic foresight study over the South America region, about the electrical grid until 2025 that considered the Climate Change phenomenon and many different energy sources, through Analytic Hierarchy Process and the Monte Carlo simulation. The evaluation considered the last Japan earthquake and nuclear plant accident in Fukushima and the technological convergence that will impact over the next 15 years in the electric grid sources. The research involved political, economic, social and technological variables. The methodology showed the Analytic Hierarchy Process ability to identify a set of variables in a strategic prospective study. Through PEST analysis and qualitative variables obtained from literature review and incorporating an expert panel, it was possible to select the most influential variable for each PEST factor. These four variables became the criteria for an Analytic Hierarchy Process model development assessed by a new expert group to reduce the convergence criteria. Then a Monte Carlo simulation was run 1000 times, between six selected alternatives. The array showed to have four prospective scenarios of the electrical grid structure to 2025 in the South America Region, using techno-economics and the socio-political criteria. The study highlighted the contribution of renewable energy with nuclear power as the main source of energy mix by 2025 .
\end{abstract}

\footnotetext{
${ }^{*}$ Corresponding author
} 
Keywords: Climate Change, Energy Sources, AHP, PEST Analysis, Monte Carlo Method

\section{Introduction}

Decisions for the construction of the electric grid through a set of energy sources should consider a host of factors associated with the environmental and economic impact of the installations; the sustainability of the electricity industry is a matter of study and debate in all societies. In addition, the accident of the nuclear plant in Fukushima, have an effect in the decisions taken regarding the capacity and composition of the electric grid.

The technological convergence of the computer, biotechnology and nanotechnology is allowing the development of photovoltaic paintings; improve the electricity distribution and nuclear fusion. The consideration of these new technologies in the study and its impact over the next 15 years it was done with the use of appropriate methodologies that include Analytic Hierarchy Process (AHP). All of the above compelled us to consider the following two research questions. First: Considering Climate Change phenomena as a global environmental problem: What would be the structure of the electric grid by the year 2025 in the South America Region? Second: How do you evaluate the impact of technological convergence?

The paper is organized as follows section provides a literature review while section 3 the methodology and analysis is described. Section 4 reveals the results and discussion and conclusions are given in section 5 and six respectively.

\section{Literature review}

For Godet, strategic foresight and planning scenarios allows to establish the conditions and actions necessary to build the best possible future, foresight should be able to identify the probable scenarios according to their probability of occurrence. Those who have the responsibility of making decisions should consider all the variables that delineate the most likely scenario through the use of methodologies validated and recognized by the scientific community to define future scenarios of a community, organization or a geographic region(Godet and MONTI, 2000; Godet et al., 1995).

In our review of the literature, the most extended and used methodologies are the Delphi method, the odds of Bayes method, the cross-impact matrix method, exploration of the environment and morphological analysis method (Glenn and Gordon, 2009).

The analytical hierarchy process (AHP), developed by Professor (Saaty, 2007, 2001), has shown great capacity of prioritizing quantitative and qualitative, this method in conjunction with the Monte Carlo simulation allows to reduce the uncertainty of the actions for decision-making(Emblemsvåg and Tonning, 2003; Liu et al., 2010). All of the above encourages us to study the phenomenon of the growth of energy consumption, its impact and decision-making of prospective scenarios using the tools described above.

\subsection{Emerging trends in electricity generation}

Fossil fuels contribute $70 \%$ of the energy consumed by the global economy(Canton, 2006). Hubbert model designates the maximum level of oil production during this decade, pushing the average price a sustained upward projection. The replacement of fossil fuels by sources cleaner to the environment, with urgency in lowering the carbon footprint, is the starting point of all the new technologies in development; based energy sources in the hydrogen, magnetism and superconductivity will no doubt be primarily responsible for the end of the era of the fuel fossil. 
Table 1. Trends of emerging power generation technologies that underpin the major changes.

\begin{tabular}{|c|c|c|c|}
\hline Category & \begin{tabular}{|l|} 
Area of knowledge \\
\end{tabular} & Applications & Potential scenario \\
\hline Materials & Physics of materials & $\begin{array}{l}\text { - Superconductivity, in which some metals and alloys } \\
\text { lead electricity without meeting resistance. }\end{array}$ & $\begin{array}{l}\text { Roads and railway with superconductors at } \\
\text { room temperature may cause super-magnetic } \\
\text { effect, capable of making vehicles and trains } \\
\text { to move through magnetic levitation. }\end{array}$ \\
\hline $\begin{array}{l}\text { Information } \\
\text { technologies }\end{array}$ & Quantum computers & $\begin{array}{l}\text { - The physicist David Deutsch, envisioned how } \\
\text { officer a tidy realizing that calculations that needed a } \\
\text { time virtually infinite in a traditional computer could } \\
\text { be done quickly in a quantum computer. }\end{array}$ & Nuclear fusion will be available. \\
\hline \multirow[t]{2}{*}{$\begin{array}{l}\text { The built } \\
\text { environment }\end{array}$} & $\begin{array}{l}\text { Nanotechnology and new } \\
\text { materials }\end{array}$ & $\begin{array}{l}\text { - Processing, storage, distribution technologies: the } \\
\text { new advanced photovoltaic catalysts (organic solar } \\
\text { cells) } \\
\text { - Nano-electronics }\end{array}$ & $\begin{array}{l}\text { - Energy generation, as through the paintable } \\
\text { solar technologies applied to buildings and } \\
\text { outdoor solar structures. } \\
\text { - Built environments capable of adapting to } \\
\text { future climates. }\end{array}$ \\
\hline & $\begin{array}{l}\text { Environmental Nanophotonics: } \\
\text { nanoscience for energy } \\
\text { efficiency and environmental } \\
\text { sustainability }\end{array}$ & $\begin{array}{l}\text { - Painted "cooling" coatings that reduces the demand } \\
\text { of energy } \\
\text { - Switchable 'smart' surfaces, properties change } \\
\text { according to conditions or needs. } \\
\text { - Nano-structured windows for more energy efficient } \\
\text { buildings. }\end{array}$ & $\begin{array}{l}\text { Reduction of the urban "heat island" effect } \\
\text { through "colder suburbs" created through the } \\
\text { application of roofs of all the buildings } \\
\text { nanostructured coatings to reflect heat. } \\
\text { • Reducing the "maximum load" energy } \\
\text { demand during the summer. }\end{array}$ \\
\hline \multirow[t]{2}{*}{$\begin{array}{l}\text { Biotechnology and } \\
\text { the environment }\end{array}$} & $\begin{array}{l}\text { Biotechnology, energy and } \\
\text { industrial production }\end{array}$ & $\begin{array}{l}\text { - Petroleum diesel and substitute fuels } \\
\text { - Conversion of lignocellulose to ethanol, biodiesel } \\
\text { from algae technologies. } \\
\text { - Bio-industry focused on crops genetically modified } \\
\text { high-value industrial engineering. }\end{array}$ & $\begin{array}{l}\text { - The transport of liquid fuel safety be } \\
\text { achieved without affecting food production / } \\
\text { security. } \\
\text { - Bioeconomy mitigates future oil shocks / } \\
\text { price rices. }\end{array}$ \\
\hline & $\begin{array}{l}\text { Biotechnology and food } \\
\text { production }\end{array}$ & $\begin{array}{l}\text { - Genetic modification }(\mathrm{GM}) \text { to change the } \\
\text { performance characteristics. }\end{array}$ & $\begin{array}{l}\text { - Access to good price essential nutrients, for } \\
\text { the rapid expansion of the world's population }\end{array}$ \\
\hline $\begin{array}{l}\text { "Clean } \\
\text { technology" }\end{array}$ & $\begin{array}{l}\text { New solutions for energy, water } \\
\text { and transportation }\end{array}$ & $\begin{array}{l}\text { - Next generation of energy systems. } \\
\text { - The adaptation of technologies for water } \\
\text { purification. } \\
\text { - Biological sequestration technologies. } \\
\text { - Functional "green wall / ceiling systems". }\end{array}$ & $\begin{array}{l}\text { - New energy technologies well adapted in } \\
\text { poor countries } \\
\text { - Charging power base renewable (for } \\
\text { example, using biomass as a source of energy } \\
\text { undervalued) } \\
\text { - Affordable and low-cost energy }\end{array}$ \\
\hline
\end{tabular}

Source: Adapted (Alford et al., 2012; Kaku, 2011; Kurzweil, 2005; National nanotechnology Initiative, 2012).

\subsection{Prospective studies for the electrical industry}

Prospective studies related to electric energy sources are divided in two phases for the next years until 2025. The literature review indicates the global installation of traditional green technologies. Wind and solar power lead investments in all continents. This first phase will be accompanied by substantial improvements in the production of uranium enriched by laser (Weinberger, 2012). This method will drastically reduce the production cost and increase the ability to obtain the product for nuclear fission plants. Finally, electric vehicles with lithium or hydrogen batteries generated a double effect on the economy of big cities; more efficient, less polluting and with storage capacities of energy equivalent to several nuclear power plants it will allow the duality in the flow of energy, vehicles may buy and sell power to the electrical grid system (Kaku, 2011).

The second phase corresponds to emerging trends associated with their convergences that will allow disconnection of the cities of large regional or national distribution networks and technologies. More efficient solar cells, photovoltaic batteries including nanotechnology and smart distribution will begin sometime in the next decade. 


\subsection{Greenhouse gas emission}

The various energy sources used in power generation bring emissions of greenhouse gases to be measured by considering the full life cycle of each project; since the construction of the project, the energy cost for the production of inputs, the energy expenditure in operation and maintenance, decommissioning and closure of the facility.

Presented in table 2, the emission values for each technology can be explained by factors specific to each installation in particular, climatic variables, energy demand and the method of production of inputs. The largest variation corresponds to the photovoltaic technology. The last few years this technology has improved ostensibly regarding energy efficiency per unit of surface and in its manufacturing process (Edenhofer et al., 2011; Laguna, 2002; Meier, 2002; Monroy, 2002; Weinberger, 2012). The first units had a broadcast life cycle comparable to fossil fuel-based computers, a decade later photovoltaic units maintain cycles similar to renewable energy (see table 2).

As an achievement, through statistical analysis of hierarchical grouping (Ward with Euclidean distance measurement methodology), we got two hierarchical groups sources with high level of gas emission greenhouses (lignite, coal, oil and Natural Gas) and the sources of low-emission (photovoltaic, biomass, Nuclear, hydropower and wind).

Table 2. Emissions of the different energy sources during the life cycle in tons of CO2 per GWH.

\begin{tabular}{lccc}
\hline \multicolumn{1}{c}{ Technology } & Average & Minimum Value & Maximum Value \\
\hline Brown coal & 1.054 & 790 & 1372 \\
Coal & 888 & 756 & 1310 \\
Oil & 733 & 547 & 935 \\
Natural gas & 499 & 362 & 891 \\
Solar photovoltaic & 85 & 13 & 731 \\
Biomass & 45 & 10 & 101 \\
Nuclear & 29 & 2 & 130 \\
Hydropower & 26 & 2 & 237 \\
Wind & 26 & 6 & 124 \\
\hline
\end{tabular}

Source: Adapted from report Comparison of Lifecycle Greenhouse Gas Emissions of Various Electricity Generation Sources (World Nuclear Association Report, 2010).

\subsection{Fukushima Effect}

The effect in the international community of the Fukushima accident gender pressures for the deactivation of nuclear power units in many countries. However, the difficulty in the short term to replace this energy source by others of less impact on climate change, taking into consideration the fear in the population regarding possible nuclear accidents, compels us to explore two alternatives of nuclear units; the equipment installed in seismic geographical areas and units planned or installed in safe areas.

\subsection{Political, social, economic and technological factors}

The impact of power generation in the community was analyzed using the PEST methodology. The involved variables were studied and grouped in the four factors mentioned above. Political variables were segmented in the levels of emission of polluting gases and the space required for its operation. The social factor in the creation of new jobs and the social acceptance of technology must be grouped. Economic variables correspond to the cost per unit of energy; this cost should be considered throughout the lifecycle of the power source. Finally, the technological factor variables are concentrated in efficiency, technological availability, availability of energy supplies and security of operation. Table 3 displays the values of the variables. 
Table 3. PEST analysis variables

\begin{tabular}{clcccccccc}
\hline Item & Technology & $\begin{array}{c}\text { Polluting } \\
\text { emissions }\end{array}$ & $\begin{array}{c}\text { Land } \\
\text { occupied }\end{array}$ & $\begin{array}{c}\text { new } \\
\text { jobs }\end{array}$ & $\begin{array}{c}\text { Social } \\
\text { rejection }\end{array}$ & Cost & $\begin{array}{c}\text { Energy } \\
\text { efficiency }\end{array}$ & $\begin{array}{c}\text { technological } \\
\text { availability }\end{array}$ & $\begin{array}{c}\text { duration } \\
\text { inputs }\end{array}$ \\
\hline Units & & $\mathrm{TCO}_{2} / \mathrm{GWh}$ & $\mathrm{Ha}$ & & $1-300$ & cents/kWH & $\%$ & $1-100$ & Years \\
\hline 1 & Brown coal & 1.054 & 2,5 & 2500 & 100 & 5,4 & 39 & 85 & 164 \\
2 & Coal & 888 & 2,5 & 2500 & 100 & 5,4 & 39 & 85 & 164 \\
3 & Oil & 733 & 2,5 & 2500 & 100 & 5,0 & 37 & 92 & 40 \\
4 & Natural gas & 499 & 2,5 & 2460 & 33 & 4 & 39 & 91 & 66 \\
5 & Solar & 85 & 35 & 5370 & 20 & 75 & 9 & 20 & 200 \\
& photovoltaic & & & & & & & & \\
6 & Biomass & 45 & 5000 & 36055 & 33 & 14 & 30 & 200 \\
7 & Nuclear & 29 & 2,5 & 2500 & 300 & 4 & 33 & 96 & 70 \\
8 & Hydropower & 26 & 750 & 2500 & 33 & 8 & 80 & 50 & 200 \\
9 & Wind & 26 & 100 & 5635 & 20 & 7 & 35 & 38 & 200 \\
\hline
\end{tabular}

Source: Adapted from (Chatzimouratidis and Pilavachi, 2008; World Nuclear Association Report, 2010).

To reduce the volume of interactions necessary for applying the AHP method between criteria and alternatives, one variable for each PEST factor was defined. Quantitative and qualitative variables were selected by the Committee of experts using the method of comparison by couple obtained the following variables for the factors; the political factor has the greenhouse effect emissions component, the economic factor used the unit cost per life cycle, social factor used social acceptance and the technological factor focused on variable security. The variable cost, emissions, and social acceptance have numerical weightings.

\section{Methodology and Analysis}

The prospective analysis of the impact of energy sources to the electricity grid considered the full lifecycle of energy sources. The methodology included a comprehensive literature review of the main actors involved in electricity generation, the development of new technologies and the control of environmental impacts from different sources. The steps of the methodology are described below and shown in Figure 1.

1. The PEST and the qualitative variables obtained from the literature review were presented to the Committee of experts, a set of variables were studied through the methodology of comparison by pairs to select the most influential variable for each PEST factor.

2. After obtaining the criteria and selected variables, it was performed AHP with the support of a new team of experts to reduce the convergence of criteria. New selection of specialists, replicated the procedure of Delphi from the RAND Corporation developed surveys during the Decade of the 60s.

3. Then a Monte Carlo simulation was used to adjust the assignments given by the respondents and define the priorities and weights of each of the evaluated technologies; the process considered to run 1000 simulations. The final results will be the fuzzy weights and the number of games won by each technology.

4. With the results, it was permitted creates four scenarios for the electric grid using a deployment axis and other socio-political axis, according to the criteria of the participants. 


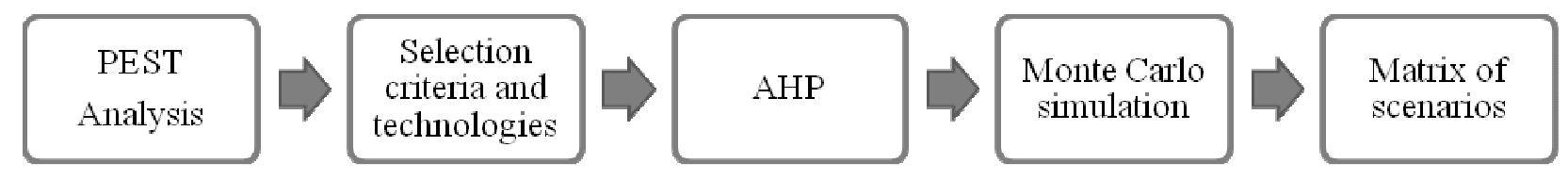

Figure 1. Flow diagram of the applied methodology (compilation, 2012)

Finally, the matrix of scenarios allowed the development of the conclusions of the research work, with priorities, consequences, and challenges of the construction of the new grid power to supply the electrical requirements for the year 2025.

\section{Results}

The results were obtained by applying the tools of analytic hierarchy process and subsequent simulation scenarios with the Monte Carlo probabilistic model. The survey for the AHP analysis was applied to all experts described in the previous section, with an VBA EXCEL ${ }^{\circledR}$ application. The advantage of using this tool is the ability to replicate the experiments, integrate the positions of all the experts, to perform sensitivity analyzes and simulate multiple scenarios with Monte Carlo.

\subsection{Analysis of hierarchical grouping of technologies.}

Through the hierarchical grouping analysis, we can visualize an initial classification of technologies. You can see the presentation of two groups, the first focuses on all the energy sources from fossil fuels, the second group is composed by two subgroups; It highlights the inclusion of nuclear energy (7) and a subgroup attending all renewable sources (Figure 2).

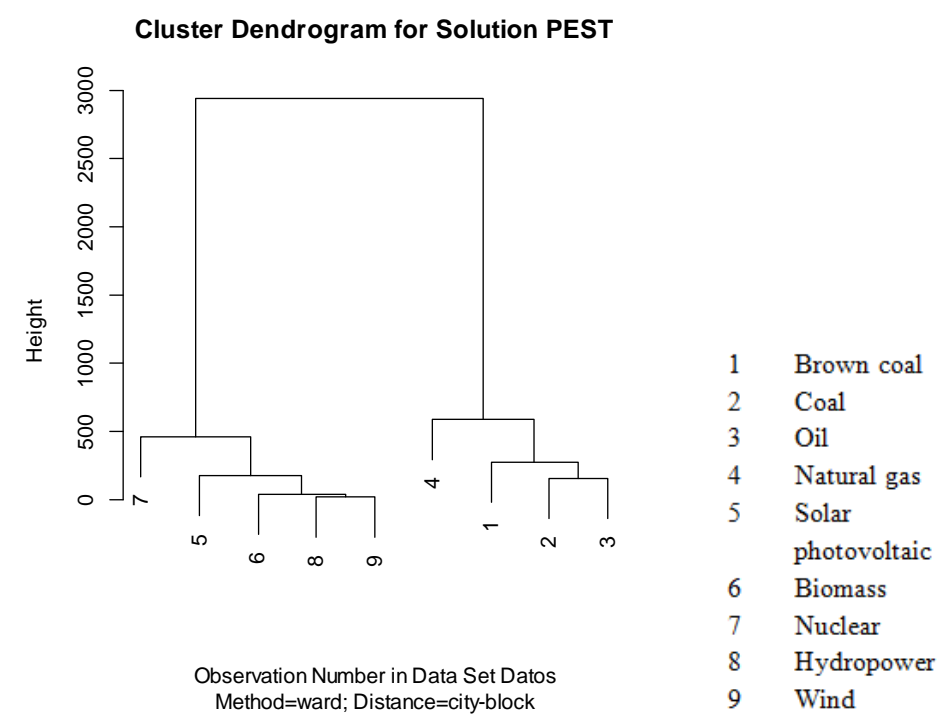

Figure 2. Variables of the PEST analysis through analysis of hierarchical grouping (software R, 2012)

\subsection{Quantitative analysis}

The relative weight of the AHP criteria is showed in table 4. They are Greenhouse effect, Unit cost per life, Social acceptance and Security. 
Table 4. AHP criteria

\begin{tabular}{|lr|}
\hline Objectives & $\begin{array}{r}\text { Relative } \\
\text { Weights (\%) }\end{array}$ \\
Greenhouse effect & 38.06 \\
Unit cost per life & 30.60 \\
Social acceptance & 8.59 \\
Security & 22.75 \\
\hline
\end{tabular}

The initial scenarios evaluated disaggregated the totality of existing technological alternatives were nine. However, the convergence of some technologies allowed us to reduce the alternatives for the later use of AHP. The alternatives selected for AHP are fourth: nuclear energy, renewable energy sources coupled with nuclear, fossil energies and fossil fuels coupled with the nuclear.

The results obtained for 1000 simulations between fourth selected technology clusters are presented in Figure 3. The simulation features predominance in the use of renewable technologies supported by nuclear sources for the energy supply of the electrical grid by the year 2025 .

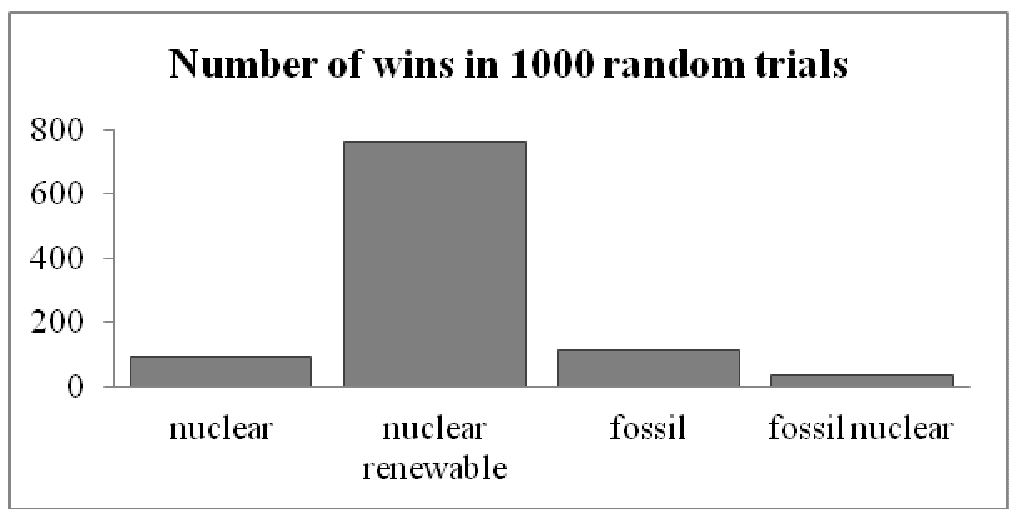

Figure 3. Monte Carlo simulation with reduction of alternatives (Excel® 2012)

\section{Discussions}

The results of the relative weights of the AHP criteria (Table 4), sensitivity analysis and Monte Carlo simulation(Fig. 3) allowed us to define potential, the weight and the sensitivity of the technologies to the PEST factors that condition the technological trends and their different degrees of uncertainty.

Previous tools and methodologies allow us to define the exploratory stages and components that identify and determine the future of the industry. The scenarios were deployed through the generation of two main axes using an axis deployments and a socio-political axis. This morphological matrix was built using the approach of the French school of prospective.

According to figure 4, there are four defined scenarios using deployments shaft in vertical position and axis socio-political in the horizontal position. The first scenario called conquering the future corresponds to the implementation globally of renewable energies as the main energy source for the electric grid, this appearance corresponds to the overcoming of the speed of technological change described by Moore's law driven by technological convergence. This scenario will only be feasible by the concurrence of political and economic factors that allow the complicity of all Governments and groups of influence to achieve a better place to live. 


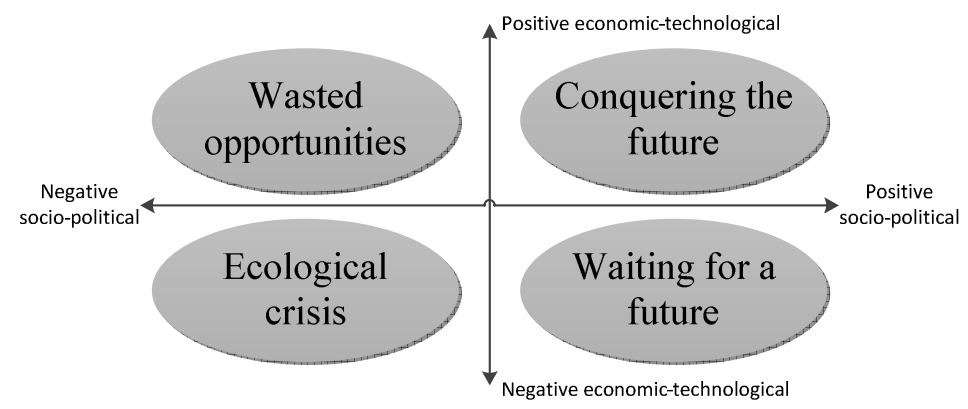

Figure 4. Scenarios of the electric grid in 2025

On the other hand, all restrictions on global energy supply policies shall establish any of the three remaining scenarios where restrictions will reduce the capabilities and benefits of clean and cheap energy for human life. The relative weight of the PEST variables reveals that the potential of energy resources lies essentially in the equilibrium of the forces of economic growth, geopolitical interests and social order.

Finally it's necessary to say that at any time can emerge new energy technologies that can change the projections, so it is advisable to use this methodology on a periodic basis and analyze trends.

\section{Conclusions}

The hybrid use of Analytic hierarchical priorities with Monte Carlo simulation process, helped understand the future supply and technological disruptions of the electrical grid in the next 15 years. Our findings can be grouped in the following way.

First, the hybridization of the hierarchical analytic process of priorities with Monte Carlo simulation reduces the uncertainty of future exploratory phenomena. The design of the prospective scenarios composed of vectors of comparison generated using AHP and simulation not deterministic Monte Carlo provides robustness to model future scenarios and is an alternative to other qualitative prospective models.

Second, analyzed the results delivered by the method hybrid AHP - Monte Carlo, it was possible to build the four prospective scenarios. The results obtained show us great instability of power systems against the political and economic factors. The survey showed as more predictable future scenario, the use of the renewable energy sources supported by nuclear sources of new generation, more efficient and sustainable with human life. However, this combination of energy sources and the associated welfare for the society only may be possible with the will of the parties involved.

Third, predictions for the next fifteen years of technological convergence we can visualize a radical change of the energy sources, reducing the impact on the environment, reduction of unit costs, the emergence of producer users and a new electrical distribution model.

Finally, an extension of this work is to investigate the study of prospective phenomena through the hybridization of AHP with techniques to predict emerging scenarios.

\section{Acknowledgements}

The authors would like to thank the Industrial Engineering Department of University of Santiago of Chile for their support. 


\section{REFERENCES}

Alford, K., Keenihan, S., McGrail, S., 2012. The Complex Futures of Emerging Technologies: Challenges and Opportunities for Science Foresight and Governance in Australia. Journal of Futures Studies 16, 67-86.

Canton, J., 2006. The Extreme Future: The Top Trends That Will Reshape the World for the Next 5, 10, and 20 Years. Dutton Adult.

Chatzimouratidis, A.I., Pilavachi, P.A., 2008. Multicriteria evaluation of power plants impact on the living standard using the analytic hierarchy process. Energy policy 36, 1074-1089.

Edenhofer, O., Pichs-Madruga, R., Sokona, Y., 2011. Renewable Energy Sources and Climate Change Mitigation: Special Report of the Intergovernmental Panel on Climate Change. Cambridge University Press.

Emblemsvåg, J., Tonning, L., 2003. Decision support in selecting maintenance organization. Journal of Quality in Maintenance Engineering 9, 11-24.

Glenn, J.C., Gordon, T.J., 2009. Futures Research Methodology: The Millennium Project: Version 3.0. Milennium Project.

Godet, M., I Buisán, E.P., Posiello, J.G., 1995. De la anticipación a la acción: Manual de prospectiva y estrategia. Alfaomega México.

Godet, M., MONTI, R.R., 2000. La caja de herramientas de la prospectiva estratégica. Gerpa.

Kaku, M., 2011. Physics Of The Future: How Science Will Shape Human Destiny And Our Daily Lives By The Year 2100 Author: Michio Kaku, Pub.

Kurzweil, R., 2005. The singularity is near: When humans transcend biology. Viking Adult.

Laguna, I., 2002. Generación de energía eléctrica y medio ambiente. Gaceta Ecológica 53-62.

Liu, G., Rasul, M.G., Amanullah, M.T.O., Khan, M.M.K., 2010. AHP and fuzzy assessment based sustainability indicator for hybrid renewable energy system, in: Universities Power Engineering Conference (AUPEC), 2010 20th Australasian. Presented at the Universities Power Engineering Conference (AUPEC), 2010 20th Australasian, pp. 1-6.

Meier, P.J., 2002. Life-cycle assessment of electricity generation systems and applications for climate change policy analysis. University of Wisconsin-Madison.

Monroy, I.L., 2002. La generación de energía eléctrica y el ambiente. Gaceta Ecológica 53-62.

National nanotechnology Initiative, 2012. National nanotechnology Initiative [WWW Document]. URL http://www.nano.gov/ (accessed 3.18.13).

Saaty, T.L., 2001. The analytic network process. Decision Making with Dependence and Feedback (2 ed.), Pittsburg: RWS Publications. 


\section{REFERENCES}

Saaty, T.L., 2007. The analytic hierarchy and analytic network measurement processes: Applications to decisions under Risk. Eur. J. Pure Appl. Math. 1, 122-196.

Weinberger, S., 2012. Laser plant offers cheap way to make nuclear fuel. Nature 487, 16-17.

World Nuclear Association Report, 2010. Comparison of Lifecycle Greenhouse Gas Emissions of Various Electricity Generation Sources. 